\title{
People with diagnosed HIV infection not attending for specialist clinical care: UK national review
}

\author{
Hilary Curtis" ${ }^{*}$, Z. Yin², K. Clay ${ }^{3}$, A. E. Brown², V. C. Delpech², E. Ong ${ }^{4}$, on behalf of the BHIVA Audit and Standards
} Sub-Committee

\begin{abstract}
Background: Regular clinical care is important for the well-being of people with HIV. We sought to audit and describe the characteristics of adults with diagnosed HIV infection not reported to be attending for clinical care in the UK.

Methods: Public Health England (PHE) provided clinics with lists of patients diagnosed or seen for specialist HIV care in 2010 but not linked to a clinic report or known to have died in 2011. Clinics reviewed case-notes of these individuals and completed questionnaires. A nested case-control analysis was conducted to compare those who had remained in the UK in 2011 while not attending care with individuals who received specialist HIV care in both 2010 and 2011.

Results: Among 74,418 adults living with diagnosed HIV infection in the UK in 2010, 3510 (4.7\%) were not reported as seen for clinical care or died in 2011. Case note reviews and outcomes were available for 2255 (64\%) of these: 456 (20.2 \%) remained in the UK and did not attend care; 590 (26.2 \%) left UK; 508 (22.6 \%) received care in the UK: 73 (3.2 \%) died and 628 (27.8\%) had no documented outcome. Individuals remaining in the UK and not attending care were more likely to be treatment naïve than those in care, but duration since HIV diagnosis was not significant. HIV/AIDS related hospitalisations were observed among non-attenders.
\end{abstract}

Conclusion: Retention in UK specialist HIV care is excellent. Our audit indicates that the 'true' loss to follow up rate in 2011 was $<2.5 \%$ with no evidence of health tourism. Novel interventions to ensure high levels of clinic engagement should be explored to minimise disease progression among non-attenders.

\section{Background}

The life expectancy of patients living with HIV has substantially improved since the advent of antiretroviral therapy (ART) in the mid-1990s. If people are diagnosed promptly, linked into HIV care, receive ART when indicated, maintain good adherence on therapy, and receive care regularly in a specialist clinic their life expectancy appears to be comparable to that of the general population [1, 2]. Furthermore, virological suppression on ART offers significant potential public health benefits in terms of prevention of onward transmission of HIV [3]. UK national guidelines

\footnotetext{
* Correspondence: hilary@regordane.net

'British HIV Association, c/o Mediscript, 1 Mountview Court, 310 Friern Barnet Lane, London N20 OLD, UK

Full list of author information is available at the end of the article
}

recommend routine screening of patients at risk of HIV acquisition [4-6] and regular care for all HIV positive individuals [7] to facilitate optimal clinical outcomes, including for example $2-4$ clinic visits annually in ART-naïve patients.

HIV treatment and care is provided free of charge to UK residents through specialist HIV outpatient clinics within the National Health Service, funded through taxation. Previous studies have shown that about $5 \%$ of individuals aged 15 years and above who receive HIV care in a given year have no linkable care or death report for the following year, and that cumulatively, an estimated one in five HIV positive patients may be lost to follow-up over a 5 year period $[8,9]$. However, the extent to which this reflects out-migration as compared with non-attendance for care among individuals 
remaining in the UK is unclear. We asked specialist HIV clinical services to review records of individuals known to be HIV positive in 2010 who had no linkable care or death report during 2011, to estimate the numbers who had remained living in the UK without attending for HIV care and who had left the UK, and to compare the non-attending group with individuals who continued receiving care.

\section{Methods}

Individuals attending specialist HIV care in England, Wales and Northern Ireland (E, W, NI) are reported annually for public health monitoring purposes via the Survey of Prevalent HIV Infections Diagnosed (SOPHID) to Public Health England (PHE, formerly Health Protection Agency), using soundex code (a 4-character coding of surname), sex, date of birth and postcode of residence to provide a unique identifier. This preserves confidentiality while enabling linking of different reports over time or across services relating to the same individual. New HIV diagnoses are similarly reported to PHE with the same variables to identify individuals. Using methods previously described [8] PHE surveillance reports of adults (16 or over) seen for specialist HIV care or newly diagnosed with HIV in 2010 were linked to corresponding SOPHID and Health Protection Scotland (HPS) reports of individuals attending specialist HIV care in 2011 anywhere in the UK. Death notifications are reported directly to PHE by clinics and are supplemented by death notifications from the Office of National Statistics; these notifications were also linked to surveillance reports of adults seen for specialist care or newly diagnosed with HIV in 2010.

Patients were categorised by whether they were diagnosed before, or during 2010 ("newly diagnosed"). Records from adults who were seen for care in 2010 but had no care or death reports in 2011 were sent securely to their care providers. Records from adults who were newly diagnosed in 2010 but had no care or death reports in both 2010 and 2011 were assigned to their clinic of diagnosis if this was a SOPHID-reporting service providing specialist HIV care, or otherwise to the nearest SOPHID-reporting service.

During October-December 2012, the British HIV Association (BHIVA) requested specialist HIV services to review case records of these individuals and complete online questionnaires. Anonymous summary data were sought for all individuals, comprising age, gender, ethnicity, country of birth, mode of HIV acquisition, whether registered with a general practitioner (GP), whether there was a record of the person having attended clinic at least once during each of the years 2010, 2011 and 2012 up to the date of submission, and patient location (in or outside UK) in 2011. To allow for fuller analysis while not unduly burdening respondents, extended data were requested for a randomly selected sample of five or 10 cases per clinical service depending on its HIV caseload (fewer or greater than 500 patients). This dataset included: year of HIV diagnosis; ART history (naïve or having been prescribed ART whether or not discontinued prior to when the person was last seen); CD4 T-cell count when last measured; clinician's assessment of attendance history and ART adherence if ART-experienced; whether the individual had declined ART during the year up to when s/he was last seen; whether attempts were made to contact the individual and/or his/her GP to encourage re-attendance; and clinical status in 2012 for those who re-attended that year. It also included information not presented here: year of arrival in the UK if born abroad; setting of HIV diagnosis (whether in UK and if so type of clinic); lowest recorded CD4 T-cell count; attendance and ART adherence; methods of contact if this was attempted; and social, psychological and economic issues.

HPS surveillance reports were not linked for individuals seen or diagnosed during 2010 in Scotland, but BHIVA asked Scottish HIV clinical services to complete the same questionnaires for individuals they had seen for care in 2010 whom they believed had not been seen for HIV care in their own or any other UK clinic during 2011.

A nested case-control analysis was conducted to determine if patients' characteristics (age, sex, ethnicity and likely mode of HIV acquisition) are associated with not receiving care (outcome). Cases were individuals who had attended for HIV specialist care in 2010 and had been reported via the online questionnaire as remaining in the UK, but not attending specialist care during 2011. Controls were individuals who received specialist HIV care in both 2010 and 2011. Cases and controls were matched by PHE centre/country in E, W, NI with an 1:10 case-control ratio.

To investigate the impacts of clinical factors (ART status and CD4 cell count) on retention, an extended case-control analysis was conducted among cases and controls with information on HIV diagnosis date, ART history and CD4 cell count in 2010 available. Thus, potential risk factors for being lost to follow up were patients' characteristics and these three clinical factors (ART history, period of HIV diagnosis and CD4 cell count).

STATA 12.0 (Stata Corp., College Station, Texas, USA) was used for analyses. Univariate and multivariate logistic regression models were used to identify significant risk factors in the case-control analyses. Proportions were presented where adults with missing information were included in analyses. Testing values and all confidence intervals (CI) are at the $95 \%$ significant level.

Ethical approval and informed consent was not required as this study was a clinical audit [10] based on data routinely collected at HIV clinics. Furthermore, clinic data collected for public health purposes are securely kept in 
strict confidence by PHE and subject to regulations made under Section 251 of the National Health Service Act 2006. No names were collected for this study.

\section{Results}

PHE and HPS received surveillance reports of 74,418 adults attending for HIV specialist care and/or newly diagnosed with HIV infection in the UK in 2010. PHE provided clinics in E, W, NI with details of 3,452 individuals with no linked 2011 care or death report, and clinics completed audit questionnaires for 2,197 (63.6\%) of these. Comparison of the distributions of age, sex, ethnicity and route of HIV infection of the 3,452 individuals with the 2,197 for whom questionnaires were completed suggested minimal response bias, with no statistically significant differences (data not shown). Clinics in Scotland completed questionnaires for a further 58 patients seen in 2010 and believed not to have received care in 2011. This resulted in a total of 3,510 individuals in the UK who were seen for care or newly diagnosed in 2010 and initially identified as not seen for care in 2011, with audit questionnaires completed for 2,255 of these (see Fig. 1). Characteristics of these individuals were as shown in Table 1.

Clinic-reported outcomes are shown in Fig. 1. Just under half of individuals who were initially identified as not seen for care in 2011 may have remained living in the UK while not receiving care. This group comprised $456(20.2 \%)$ individuals recognised as having been in the UK and out of care (see Table 1) and a further 628 $(27.8 \%)$ with unknown outcomes (of which: not known whether in UK 578, $25.6 \%$; not identifiable from information provided by PHE 50, $2.2 \%$ ). The remainder were accounted for by departure from the UK (590, $26.2 \%$ ), having received care $(508,22.6 \%)$ or having died $(73$,
$3.2 \%$ - this is additional to individuals for whom PHE had identified a linked death report). Strong evidence for 427 individuals having left the UK included documented plans to leave or a request for a clinician letter to an overseas care provider (385 cases), information from immigration authorities (28) or prisons (2), and the patient contacting the clinic from abroad (7) or reporting having been abroad in 2011 when returning to care in 2012 (5). In 71 cases the evidence was less clear, eg simply a record that the person had left the UK, and for 92 individuals this question was not answered.

Extended data were provided for 230 individuals who remained in the UK and who were not in receipt of care in 2011. Of these, $112(48.7 \%)$ had a history of irregular attendance and there were significant adherence concerns for 27 (23.9 \% of 113 with ART experience), but only $30(13.0 \%)$ had declined ART in the year up to when they were last seen. Of the 230 individuals, 97 (42.2\%) re-presented for care during 2012 prior to data collection in October-December, including 28 (12.2 \%) with symptomatic illness among whom there were 9 inpatient admissions and 7 AIDS-defining diagnoses. Clinics reported attempts to contact $183(79.6 \%)$ of these 230 individuals to encourage them to return to care, but although 124 (53.9 \%) were registered with a GP who was aware of their HIV status, clinics contacted the GP in only $69(30.0 \%)$ cases.

Of 456 individuals who were recognised as having remained in the UK but not attended for specialist care in 2011, 308 had complete demographic information and were included in regression analyses. Of these 308 individuals, extended data were available for 136 individuals. In univariate analysis, individuals who received specialist HIV care in 2010 and remained in the UK but not

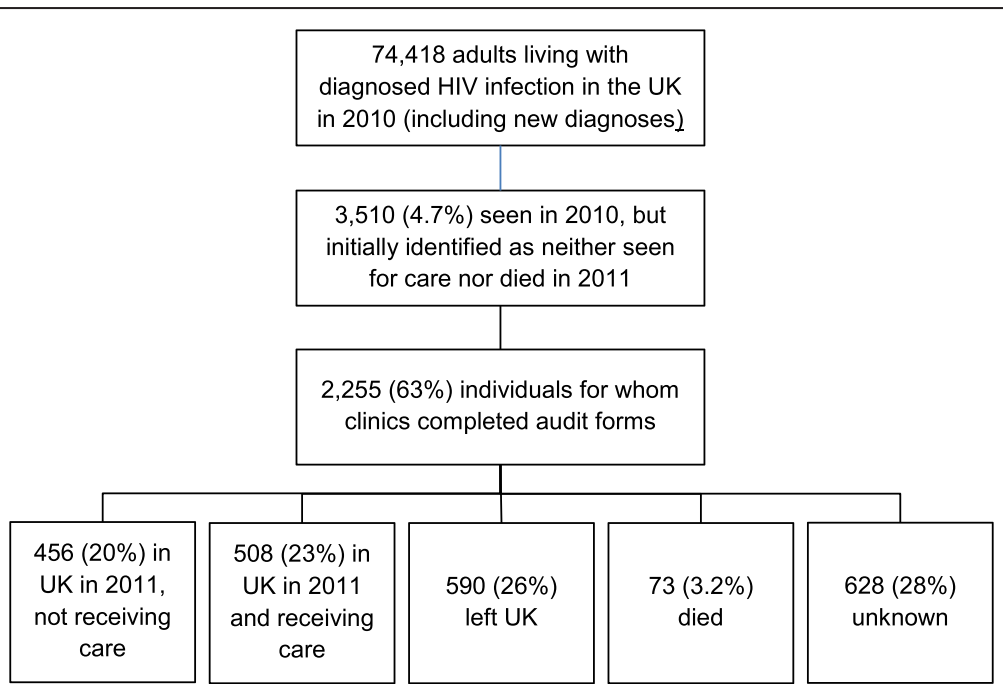

Fig. 1 Flowchart showing study inclusion and outcomes for 2255 adults (16 or over) with diagnosed HIV infection 
Table 1 Characteristics of all individuals initially identified as not seen for care in 2011 for whom audit forms were completed, and of those reported by the clinic as remaining in the UK and not receiving care

\begin{tabular}{|c|c|c|c|}
\hline Characteristic & $\begin{array}{l}\text { Number (\%) of individuals for } \\
\text { whom audit questionnaire } \\
\text { completed }\end{array}$ & $\begin{array}{l}\text { Number (\%) of individuals } \\
\text { remaining in UK and not } \\
\text { receiving care during } 2011\end{array}$ & $\begin{array}{l}\text { Number (\%) of individuals remaining in } \\
\text { UK and not receiving care during } 2011 \\
\text { with complete demographic information }\end{array}$ \\
\hline Total & $2255(100)$ & $456(100)$ & $308(100)$ \\
\hline \multicolumn{4}{|l|}{ Sex: } \\
\hline Male & $1,290(57.2)$ & $175(38.4)$ & $178(57.8)$ \\
\hline Female & $838(37.2)$ & $272(59.6)$ & $130(42.2)$ \\
\hline Trans-gender & $5(0.2)$ & $1(0.2)$ & 0 \\
\hline Not known/stated & $122(5.4)$ & $8(1.8)$ & 0 \\
\hline \multicolumn{4}{|l|}{ Age: } \\
\hline 16-19 & $9(0.4)$ & $2(0.4)$ & $1(0.3)$ \\
\hline $20-29$ & $310(13.7)$ & $76(16.7)$ & $45(14.6)$ \\
\hline $30-39$ & 765 (33.9) & $167(36.6)$ & $115(37.3)$ \\
\hline $40-49$ & 717 (31.8) & 144 (31.6) & $97(31.5)$ \\
\hline $50-59$ & $274(12.2)$ & $53(11.6)$ & $41(13.3)$ \\
\hline $60+$ & $103(4.6)$ & $10(2.2)$ & $9(2.9)$ \\
\hline Not known/stated & $77(3.4)$ & $4(0.9)$ & $0(0)$ \\
\hline \multicolumn{4}{|l|}{ Ethnicity: } \\
\hline Black-African & $1,028(45.6)$ & $214(46.9)$ & $172(55.8)$ \\
\hline White & $846(37.5)$ & 179 (39.3) & $136(44.2)$ \\
\hline Other & $284(12.6)$ & $58(12.7)$ & $0(0)$ \\
\hline Not known/stated & $97(4.3)$ & $5(1.1)$ & $0(0)$ \\
\hline \multicolumn{4}{|l|}{ Birthplace: } \\
\hline UK & $600(26.6)$ & $176(38.6)$ & $114(37.0)$ \\
\hline Outside UK & $1,383(61.3)$ & $246(53.9)$ & $176(57.1)$ \\
\hline Not known/stated & $272(12.1)$ & $34(7.5)$ & $18(5.8)$ \\
\hline \multicolumn{4}{|l|}{ a'Likely mode of HIV acquisition: } \\
\hline Heterosexual sex & $1,320(58.5)$ & $277(60.7)$ & $202(65.6)$ \\
\hline Sex between men & $726(32.2)$ & $148(32.5)$ & $106(34.4)$ \\
\hline Injecting drug use & $64(2.8)$ & $14(3.1)$ & $0(0)$ \\
\hline Receipt of blood/blood products & $22(1.0)$ & $1(0.2)$ & $0(0)$ \\
\hline Vertical infection & $16(0.7)$ & $6(1.3)$ & $0(0)$ \\
\hline Other & $11(0.5)$ & $0(0.0)$ & $0(0)$ \\
\hline None stated & $134(5.9)$ & $16(3.5)$ & $0(0)$ \\
\hline
\end{tabular}

${ }^{a}$ More than one mode of HIV acquisition could be selected

in receipt of such care in 2011 were more likely to be female, heterosexually exposed (cf male homosexual), black-African (cf white), younger, recently diagnosed, ART-naïve and with a low CD4 T-cell count than individuals who received specialist HIV care in both 2010 and 2011 (Table 2). In multivariable analysis based on demographic summary data, black-African ethnicity and younger age remained significantly associated with not being in receipt of care in 2011. When the multivariable analysis was expanded to include factors in the extended dataset (year of HIV diagnosis, ART status and
CD4 T-cell count) being ART-naïve and low CD4 T-cell count were the only factors significantly associated with not being in receipt of care in 2011, while age and ethnicity ceased to be significant.

\section{Discussion}

Among adults seen for care or diagnosed with HIV in 2010 without a linkable care or death report for 2011, clinics recognised only a fifth $(20.2 \%)$ as having remained in the UK but not in receipt of specialist HIV care, while a further $27.8 \%$ had unknown outcomes and 
Table 2 Associations from univariate and multivariable logistic regression models between demographic and clinical factors and retention in care in 2011

\begin{tabular}{|c|c|c|c|}
\hline & Univariate analysis: & $\begin{array}{l}\text { Multivariable analysis of summary } \\
\text { data for } 308 \text { cases, } 3080 \text { controls: }\end{array}$ & $\begin{array}{l}\text { Multivariable analysis of extended } \\
\text { data for } 136 \text { cases, } 2313 \text { controls: }\end{array}$ \\
\hline & Odds ratio $(95 \% \mathrm{Cl})$ & Odds ratio (95\% Cl) & Odds ratio $(95 \% \mathrm{Cl})$ \\
\hline \multicolumn{4}{|l|}{ Sex: } \\
\hline Male & Ref & Ref & Ref \\
\hline Female & $1.30(1.02-1.64)$ & $0.83(0.61-1.14)$ & $1.19(0.73-1.93)$ \\
\hline \multicolumn{4}{|l|}{ Age: } \\
\hline $16-19$ & $0.92(0.11-7.63)$ & $0.79(0.09-6.66)$ & $1.34(0.12-14.51)$ \\
\hline $20-29$ & Ref & Ref & Ref \\
\hline $30-29$ & $0.76(0.52-1.09)$ & $0.70(0.48-1.01)$ & $0.89(0.49-1.62)$ \\
\hline $40-49$ & $0.52(0.36-0.76)$ & $0.48(0.33-0.71)$ & $0.89(0.48-1.62)$ \\
\hline $50-59$ & $0.57(0.37-0.90)$ & $0.56(0.35-0.88)$ & $0.54(0.24-1.21)$ \\
\hline $60+$ & $0.36(0.17-0.75)$ & $0.39(0.18-0.82)$ & $0.73(0.23-2.32)$ \\
\hline \multicolumn{4}{|l|}{ Ethnicity: } \\
\hline White & Ref & Ref & Ref \\
\hline Black-African & $1.67(1.32-2.11)$ & $1.66(1.14-2.43)$ & $1.66(0.92-2.97)$ \\
\hline \multicolumn{4}{|l|}{ Likely mode of HIV acquisition: } \\
\hline Male homosexual & Ref & Ref & Ref \\
\hline Heterosexual & $1.52(1.19-1.94)$ & $1.14(0.75-1.73)$ & $1.33(0.69-2.58)$ \\
\hline Year of diagnosis: & & Not in summary data & \\
\hline 2008 or earlier & Ref & & Ref \\
\hline $2009-10$ & $2.23(1.52-3.25)$ & & $1.03(0.65-1.62)$ \\
\hline ART before 2012: & & Not in summary data & \\
\hline History of ART & Ref & & Ref \\
\hline No ART & $9.15(6.47-12.93)$ & & $12.12(7.87-18.64)$ \\
\hline Last CD4 T-cell count in 20112010 (cells/mm³) & & Not in summary data & \\
\hline $0-200$ & Ref & & Ref \\
\hline $201-350$ & $0.79(0.41-1.51)$ & & $0.70(0.34-1.45)$ \\
\hline $351-500$ & $0.39(0.20-0.74)$ & & $0.24(0.11-0.52)$ \\
\hline $500+$ & $0.36(0.20-0.66)$ & & $0.26(0.13-0.52)$ \\
\hline
\end{tabular}

may have been in the same situation. Of the remainder, $26.2 \%$ had left the UK, $22.6 \%$ were reported to have received care and $3.2 \%$ had died. Previous studies have shown that for a given year no linkable care or death report can be found for about $5 \%$ of adults who attended for specialist HIV care in the preceding year $[8,9]$. Our study suggests that non-attendance for care among individuals remaining in the UK accounts for at most about a half of this, even if those with unknown outcomes are assumed to have been out of care in the UK. This represents an excellent rate of retention in care within the UK.

Although this finding is encouraging, non-attendance for care among individuals with diagnosed HIV remains a public health concern in terms of both disease progression and potential onward transmission of infection, especially in view of unsuppressed viraemia in the absence of ART. We were not able to investigate transmission risks, but of 230 individuals remaining in the UK and not receiving care in 2011, 28 (12.2 \%) re-attended with symptomatic illness in 2012 including 9 requiring inpatient care and 7 with AIDS-defining diagnoses. While it is not possible to calculate incidence rates from our data, this appears substantially higher than in the UK-CHIC cohort of patients with established HIV infection (Sabin C, personal communication), illustrating the risk of disease progression among individuals not attending for care.

In a multivariable case-control analysis, individuals remaining in the UK who received specialist HIV care in 2010 but not in 2011 were more likely to be ART naïve 
and to have a low CD4 T-cell count than those who received care in both years, although the $\mathrm{CD} 4$ finding may simply be a reflection of non-use of ART. Duration since HIV diagnosis was not significant in this analysis, suggesting that non-attendance remains an ongoing risk among individuals not on ART. Black-African ethnicity has previously been shown to be associated with loss to follow up from UK HIV clinical care $[8,9]$. We found that this is not solely due to out-migration from the UK since in multivariable analysis based on demographic factors, individuals remaining in the UK but not receiving care were more likely to be black-African.

Out-migration from the UK accounted for over a quarter of individuals lacking a linked care report for 2011 or death report. As we have reported previously [11] this mainly involved previous long term residents, and does not indicate use of specialist HIV care services by short-term visitors.

According to clinic-reported outcomes, 508 (22.6 \%) individuals for whom PHE had not identified a linked 2011 care or death report had received HIV care in the UK that year, and 73 (3.2\%) had died. Some of these discrepancies may reflect mistaken assumptions, for example if a patient was believed to have transferred his/her care to a different clinic but had not in fact attended there. However, 163 individuals were reported to have attended the same clinical service in 2011 as in 2010; this may be explained by incomplete reporting to PHE, changes in personal identifiers and limitations of the data linking method.

In most cases HIV specialist services took active steps to re-engage with patients whom they recognised as not being in receipt of care, but these services only involved the GP in 69 of 124 cases in which the latter was aware of the patient's HIV status. This may reflect specific historical circumstances in much of the UK, where specialist HIV care is delivered via genitourinary medicine clinics set up to provide highly confidential care for people with sexually transmitted infections. However it represents a missed opportunity to collaborate to enable more effective access to care.

Limitations of our study include reliance on case note information collected retrospectively from clinics. This led to considerable uncertainties and may possibly have resulted in misclassification, reflecting the fact that clinics often have limited information about people who do not attend for care. Outcomes were unknown for 628 (27.8 \%) of cases and, as stated above, clinics may have incorrectly reported some individuals as having received care, eg in a mistaken belief that they had transferred to a different clinic. Completed audit forms were obtained for only 2,197 (63.6\%) of 3,452 individuals initially identified via record linkage as not seen for care. It is possible that clinics may have been more likely to respond in cases where they had better information, but we did not detect response bias based on demographic factors. Also, we only examined nonretention in care from 2010 to 2011 and return to care in 2012, rather than cumulative movement in and out of care over multiple years. This means the number of people living in the UK with diagnosed HIV who are not receiving care cannot be estimated from our data. A previous study found that cumulatively $19 \%$ of individuals seen for care during 1998-2006 became lost to follow up based on SOPHID record linking [8], but did not include clinic-held information such as out-migration from the UK. In addition PHE data shows that over $80 \%$ of individuals in England have a CD4 measurement within three months after initial HIV diagnosis [12], indicating that the vast majority become linked into a specialist HIV care service.

\section{Conclusions}

Our study confirmed excellent retention in care among UK adults with HIV, but also the high risk of disease progression among non-attenders. Public health initiatives aimed at maintaining those at greatest risk of suboptimal attendances in care remain essential.

\section{Abbreviations}

AIDS: Acquired immunodeficiency syndrome; ART: Antiretroviral therapy; BHIVA: British HIV Association; CD4: CD4+ T-helper lymphocyte;

Cl: Confidence interval; E, W, Nl: England, Wales and Northern Ireland; GP: General (medical) practitioner; HIV: Human immunodeficiency virus; HPS: Health Protection Scotland; PHE: Public Health England; SOPHID: Survey of Prevalent HIV Infections Diagnosed; UK: United Kingdom.

\section{Competing interests}

The authors declare that they have no competing interests.

\section{Authors' contributions}

$\mathrm{HC}$ designed the questionnaires and analysed anonymous data received by BHIVA. ZY and AEB performed record linking and case control analysis. VCD oversaw the record linking procedure, planned the case control analysis and revised the manuscript. $\mathrm{HC}, \mathrm{KC}$ and $\mathrm{EO}$ conceived of and designed all other aspects of the study together with the BHIVA Audit and Standards

Sub-Committee. HC and KC prepared the manuscript, which all authors read and approved.

\section{Acknowledgements}

The following individuals were members of the BHIVA Audit and Standards Sub-Committee during 2012-3: J Anderson, D Asboe, S Bhagani, A Brown, F Burns, D Churchill, K Clay, A De Ruiter, V Delpech, M Desai, K Doerholt, S Edwards, S Ellis, A Freedman, Y Gilleece, P Gupta, A Judd, S Morris, J Musonda, D Ogden, C Okoli, E Ong, O Olarinde, A Palfreeman, R Pebody, F Post, M Rayment, A Rodger, C Sabin, A Schwenk, A Sullivan, H Veerakathy, E Wilkins. The authors and committee would like to thank clinicians who submitted data from the following services: Woolmanhill Hospital, Aberdeen; Monklands Hospital, Airdrie; Ashton Primary Care Centre, Ashton-under-Lyne; Buckinghamshire PCT, Aylesbury; Preston Hall Hospital, Aylesford; Orchard Health Centre, Banbury; Barking Hospital, Barking; Barnet General Hospital, Barnet; Basingstoke and North Hampshire NHS Foundation Trust, Basingstoke; Royal United Hospital, Bath; Beckenham Hospital, Beckenham; Bedford Hospital, Bedford; Royal Hospitals Trust, Belfast; Birmingham Heartlands Hospital, Birmingham; Queen Elizabeth Hospital, Birmingham; Whitegate Health Centre, Blackpool; Royal Bournemouth Hospital, Bournemouth; Bradford Hospitals NHS Trust, Bradford; Royal Sussex County Hospital, Brighton; Southmead Hospital, Bristol; West Suffolk Hospital, Bury St Edmunds; Addenbrooke's Hospital Hospital NHS Trust, Cambridge; Kent \& Canterbury Hospital, Canterbury; Cardiff Royal Infirmary, Cardiff; St Helier Hospital, Carshalton; Mid Essex Hospital Services NHS Trust, Chelmsford; Cheltenham General Hospital, Cheltenham; St Peter's Hospital, Chertsey; 
Countess of Chester Hospital NHS Trust, Chester; Chesterfield Royal Hospital NHS Foundation Trust, Chesterfield; St Richard's Hospital, Chichester; Essex County Hospital, Colchester; City of Coventry Health Centre, Coventry; Crawley Hospital, Crawley; Mayday University Hospital, Croydon; Darent Valley Hospital, Dartford; Dewsbury and District Hospital, Dewsbury; Doncaster Royal Infirmary, Doncaster; Avenue House Sexual Health Clinic, Eastbourne; Royal Infirmary of Edinburgh, Edinburgh; Western General Hospital, Edinburgh; Exeter NHS Walk-in Centre, Exeter; Medway Maritime Hospital, Gillingham; Gartnaval General Hospital, Glasgow; Gloucestershire Royal \& East Gloucestershire NHS Trusts, Gloucester; Orsett Hospital, Grays; James Paget Hospital NHS Trust, Great Yarmouth; Grimsby Hospital, Grimsby; Farnham Road Hospital, Guildford; Princess Alexandra Hospital, Harlow; Northwick Park Hospital, Harrow; Ore Clinic, Hastings; Wycombe General Hospital, High Wycombe; Huddersfield Royal Infirmary, Huddersfield; Conifer House, Hull; Oak Tree Centre, Huntingdon; Ipswich Hospital, Ipswich; Queen Elizabeth Hospital, King's Lynn; Forth Park Hospital, Kirkcaldy; Leeds Teaching Hospitals NHS Trust, Leeds; Leeds General Infirmary, Leeds; Leicester Royal Infirmary, Leicester; Royal Liverpool University Hospital, Liverpool; St Thomas' Hospital, London; Homerton University Hospital NHS Foundation Trust, London; King's College Hospital, London; Newham University Hospital NHS Trust, London; North Middlesex Hospital, London; Queen Elizabeth Hospital, London; Queen Mary's University Hospital, London; Mortimer Market Centre, London; Royal Free Hospital, London; Barts and the London Hospital, London; St Ann's Hospital, London; St George's Hospital, London; Imperial College Healthcare NHS Trust, London; Central Middlesex Hospital, London; Chelsea and Westminster Hospital, London; Whipps Cross Hospital, London;

Loughborough General Hospital, Loughborough; Luton \& Dunstable Hospital NHS Trust, Luton; Macclesfield District Hospital, Macclesfield; Withington Hospital, Manchester; Manchester Royal Infirmary, Manchester; James Cook University Hospital, Middlesbrough; West Middlesex University Hospital, Middlesex; New Croft Sexual Health Centre, Newcastle upon Tyne; Royal Victoria Infirmary, Newcastle upon Tyne; Royal Gwent Hospital, Newport; St Mary's Hospital, Newport; Norfolk \& Norwich University Hospital, Norwich; Nottingham City Hospital, Nottingham; Nottingham City Hospital, Nottingham; Royal Oldham Hospital, Oldham; Oxford Radcliffe NHS Trust, Oxford; Peterborough and Stamford NHS Foundation Trust, Peterborough; Derriford Hospital, Plymouth; St Mary's Hospital, Portsmouth; Royal Berkshire and Battle Hospital, Reading; Surrey Primary Care Trust, Redhill; Doncaster \& Bassetlaw Hospitals NHS Foundation Trust, Retford; Rotherham NHS Foundation Trust, Rotherham; Hospital of St Cross, Rugby; Lance Burn Sexual Health Centre, Salford; Salisbury District Hospital, Salisbury; Royal Hallamshire Hospital, Sheffield; Royal Hallamshire Hospital, Sheffield; One to One Centre, Shiremoor; Southlands Hospital, Shoreham by Sea; Royal Shrewsbury Hospital, Shrewsbury; Upton Hospital, Slough; Ealing Hospital, Southall; St Helen's and Knowsley Hospital, St Helens; Jersey General Hospital, St Helier; Kingsway Health Centre, Stevenage; Staffordshire and Stoke on Trent Partnership, Stoke-on-Trent; Sunderland Royal Hospital, Sunderland; Sherwood Forest Hospitals NHS Trust, Sutton-in-Ashfield; Singleton Hospital, Swansea; The Great Western Hospital, Swindon; Musgrove Park Hospital, Taunton; Princess Royal Hospital NHS Trust, Telford; Royal Cornwall Hospital, Truro; Kent \& Sussex Hospital, Tunbridge Wells; The Hillingdon Hospital, Uxbridge; King Street Health Centre, Wakefield; Manor Hospital, Walsall; Warrington Hospital, Warrington; South Warwickshire General Hospitals NHS Trust, Warwick; West Hertfordshire Hospital NHS Trust, Watford; Sandwell District General Hospital, West Bromwich; Southend Hospital, Westcliffe on Sea; Weymouth Community Hospital, Weymouth; Royal Hampshire County Hospital, Winchester; Arrowe Park Hospital, Wirral; New Cross Hospital, Wolverhampton; Wrexham Maelor Hospital, Wrexham.

\section{Author details}

${ }^{1}$ British HIV Association, c/o Mediscript, 1 Mountview Court, 310 Friern Barnet Lane, London N20 OLD, UK. ${ }^{2}$ Public Health England, London, UK. ${ }^{3}$ Heartlands Hospital, Birmingham, UK. ${ }^{4}$ Department of Infection \& Tropical Medicine, Royal Victoria Infirmary, Newcastle, UK.

Received: 12 November 2014 Accepted: 16 July 2015 Published online: 06 August 2015

\section{References}

1. Nakagawa F, May M, Phillips A. Life expectancy living with HIV: recent estimates and future implications. Curr Opin Infect Dis. 2013;26:17-25.
2. May M, Gompels M, Delpech V, Porter K, Orkin C, Kegg S et al. Impact on life expectancy of HIV-1 positive individuals of CD4+ cell count and viral load response to antiretroviral therapy: UK cohort study. AIDS. 2014;28:1193-202. doi:10.1097/QAD.0000000000000243.

3. Cohen MS, Chen YQ, McCauley M, Gamble T, Hosseinipour MC, Kumarasamy $\mathrm{N}$ et al. Prevention of HIV-1 infection with early antiretroviral therapy. N Engl J Med. 2011;365:493-505.

4. British HIV Association, British Association for Sexual Health and HIV, British Infection Society. UK National Guidelines for HIV Testing 2008. London: British HIV Association; 2008. http://www.bhiva.org/HIV-testingguidelines.aspx.

5. National Institute for Health and Care Excellence. Increasing the uptake of HIV testing among black Africans in England. London: NICE; 2011. http://www.nice.org.uk/guidance/ph33.

6. National Institute for Health and Care Excellence. Increasing the uptake of HIV testing among men who have sex with men. London: NICE; 2011. http://www.nice.org.uk/guidance/ph34.

7. Asboe D, Aitken C, Boffito M, Booth C, Cane P, Fakoya A et al. British HIV Association guidelines for the routine investigation and monitoring of adult HIV-1-infected individuals 2011. HIV Med. 2012;13:1-44.

8. Rice BD, Delpech VC, Chadborn TR, Elford J. Loss to follow-up among adults attending human immunodeficiency virus services in England, Wales, and Northern Ireland. Sex Trans Dis. 2011;38:685-90.

9. Gerver SM, Chadborn TR, Ibrahim F, Vatsa B, Delpech VC, Easterbrook PJ. High rate of loss to clinical follow up among African HIV-infected patients attending a London clinic: a retrospective analysis of a clinical cohort. J Int AIDS Soc. 2010;13:1-10.

10. Brain J, Schofield J, Gerrish K, Mawson S, Mabbott I, Patel D et al. A guide for clinical audit, research and service review. London: Healthcare Quality Improvement Partnership; 2011.

11. Delpech V, Curtis H, Brown AE, Ong E, Hughes G, Gill N. Migrant patients' access to HIV care: testing should always be free. Br Med J. 2013;347:f7056. http://dx.doi.org/10.1136/bmj.f7056.

12. Brown AE, Kall MM, Smith RD, Yin Z, Hunter A, Delpech VC. Auditing national HIV guidelines and policies: The United Kingdom CD4 Surveillance Scheme. Open AIDS J. 2012;6:149-55. doi:10.2174/1874613601206010149.

\section{Submit your next manuscript to BioMed Central and take full advantage of:}

- Convenient online submission

- Thorough peer review

- No space constraints or color figure charges

- Immediate publication on acceptance

- Inclusion in PubMed, CAS, Scopus and Google Scholar

- Research which is freely available for redistribution 